\title{
Systematic Surgical Exploration or Observation and Selective Exploration of Suspected Traumatic Mesenteric and Bowel Injuries: A Meta-analysis
}

\author{
Yigit Duzkoylu ${ }^{1, *}$, Mehmet Akif Ustuner ${ }^{1}$, Nesrin Turhan ${ }^{2}$ and Erdal Birol Bostanci ${ }^{1}$ \\ ${ }^{1}$ Gastroenterological Surgery Clinic, Turkiye Yuksek Ihtisas Education and Research Hospital, Ankara, Turkey \\ 2 Pathology Department, Turkiye Yuksek Ihtisas Education and Research Hospital, Ankara, Turkey
}

* Corresponding author: Yigit Duzkoylu, Gastroenterological Surgery Clinic, Turkiye Yuksek Ihtisas Education and Research Hospital, Ankara, Turkey. Tel: +905332612533; Email: dryigit@gmail.com

Received 2021 January 10; Revised 2021 February 01; Accepted 2021 March 11.

\begin{abstract}
Context: Mesenteric and bowel injuries (MBI) are rare and dangerous presentations of blunt abdominal trauma and often cause clinical uncertainty since their diagnosis is difficult and operative treatments are often delayed. No clear guidelines exist regarding this topic, and due to the rarity of the injury, few and highly low-quality data are available. This study aimed to compare early surgical exploration, delayed surgical exploration, and non-operative management in patients with proven and suspected blunt MBI.

Evidence Acquisition: Detailed research was performed on Medline, Embase, PubMed, Cochrane Central Register of Controlled Trials, and Cochrane Database of Systematic Reviews databases until 29th November 2019. The studies that were considered eligible to be included in this systematic review and consequent meta-analysis were those focusing on patients with proven MBI or computed tomography (CT) signs suspected for them and comparing early surgical exploration (EOR) with delayed one (DOR) or with selective surgical exploration (SOR) after clinical observation. The eligible studies were sub-grouped into those using a delay cut-off (to distinguish "early" and "deferred" surgical intervention) higher than $12 \mathrm{~h}$ and those using a cut-off lower than $12 \mathrm{~h}$, as well as those focusing on patients with high-risk CT signs (pneumoperitoneum and active mesenteric bleeding) and those focusing on patients with low-risk ones. Results: Finally, 16 studies fulfilled the inclusion criteria and were included in the meta-analysis with a total of 2,702 patients. All studies, although not randomized, were considered to be at the acceptable risk of bias in the important domains. It was found that in patients with proven MBI, in the subgroup of studies with a delay cut-off for surgical intervention lower than $12 \mathrm{~h}$, the complication rate was significantly lower in EOR, compared to DOR (risk ratio $[\mathrm{RR}]=0.47,95 \% \mathrm{CI}=0.29-0.79, \mathrm{P}=0.004$ ). In patients with suspected MBI with lowrisk CT signs, the complication rate was significantly lower in $\mathrm{SOR}$, compared to $\mathrm{EOR}$ ( $\mathrm{RR}=1.79,95 \% \mathrm{CI}=1.27-2.53$, $\mathrm{P}=0.001)$. It was also revealed that in patients with high-risk CT signs, the complication rate and the length of stay (LOS) were significantly lower in EOR, compared to DOR (complication: $\mathrm{RR}=0.38,95 \% \mathrm{CI}=0.17-0.84, \mathrm{P}=0.02$; LOS: mean difference $=-12.00,95 \% \mathrm{CI}=-21.44-2.56, \mathrm{P}=0.01$ ).

Conclusion: The present meta-analysis confirmed that in patients with proven blunt MBI a delay of surgical intervention higher than $12 \mathrm{~h}$ would lead to a higher complication rate and a longer LOS. Based on the results, in blunt trauma patients with pneumoperitoneum or active mesenteric bleeding at the admission CT scan, complications and LOS could be reduced by performing an early surgical exploration. On the other hand, in blunt trauma patients with low-risk CT signs of suspected MBI, a clinical observation with selective surgical exploration in case of clinical or radiological worsening could reduce the complication rate without increasing mortality and LOS.
\end{abstract}

Keywords: Abdominal trauma index, Bowel

\section{Context}

The management of traumatic solid organ injury, with the majority of patients being managed nonoperatively, has been regulated by shared international guidelines (1-4), and indication for conservative or operative management in this group of patients is well understood. On the contrary, mesenteric and bowel injuries (MBI) are rare consequences of blunt abdominal trauma and often cause clinical uncertainty. Although MBIs are rare (5), patients with bowel injuries have a high mortality rate, ranging from $1.3 \%-19.8 \%(5,6)$. Despite technological innovation, MBI diagnosis remains challenging. Computed tomography (CT) scans fail to detect MBI in a significant number of patients in $4 \%-25 \%$ of cases $(5,7,8)$, with reported insufficient sensibility and specificity of CT scans (5, 8). As a result of the difficult diagnosis and sporadic exposure of surgeons (especially of non-trauma surgeons) to MBIs and the rarity of these injuries, their treatment is often subjected to delay.

There is a considerable debate regarding distinguishing patients with suspected MBI needing urgent surgical exploration from those who can receive clinical observation, to prevent septic complications and, at the same time, minimizing negative exploration rates. Furthermore, no consensus exists among researchers on the real relationship between the delay of operative intervention in MBI and the increase in mortality and complication rate $(6,7,9-14)$, as well as on the rate of non-therapeutic surgical intervention (negative surgical exploration or findings which do not require surgical repair) $(7,9-12,15,16)$. Some pieces of evidence are available for penetrating hollow-viscus injuries (17); however, no clear guidelines exist for the diagnosis and treatment of 
MBI after blunt trauma. Nevertheless, in trauma and emergency surgery setting, it is very difficult to perform randomized controlled trials and obtain high-quality data. To the best of our knowledge, no meta-analysis has been performed on the mentioned issues yet to collect and analyze them. The present meta-analysis aimed to compare, in blunt trauma patients undergoing surgery with proven MBI or with CT signs of suspected MBI, the outcomes of early surgical intervention (Early Operative Room [EOR]) with outcomes of deferred surgery (Deferred Operative Room [DOR]). Moreover, it was conducted to compare, in blunt trauma patients with CT signs of suspected MBI, the outcomes of EOR with those of clinical observation and selective surgical exploration in patients with clinical or radiological worsening (onset of sepsis or peritonism, worsening of CT-scan signs) (Selective Operative Room [SOR]).

\section{Evidence Acquisition}

\subsection{Literature search strategy}

Electronic searches were performed in Medline, Embase, PubMed, Cochrane Central Register of Controlled Trials, and Cochrane Database of Systematic Reviews databases until 29th November 2019. The search process was conducted using the following keywords: "Bowel", "Hollow viscus", "Mesenteric trauma", "Mesenteric injury", "Mesenteric bleeding", "Mesenteric hematoma", "Mesenteric hemorrhage", "Mesenteric embolization", and "Blunt trauma" combined with AND/OR. The reference lists of all retrieved articles were reviewed for further identification of potentially relevant studies. Review articles were also obtained to determine other possible studies.

\subsection{Selection criteria}

The studies determined as eligible for this systematic review and consequent meta-analysis were those comparing EOR with DOR or SOR in patients with proven MBI or CT signs suspected for MBI after blunt abdominal trauma. In this study, EOR means immediate surgical exploration (exploratory laparoscopy or laparotomy) for bowel or mesenteric injuries after a patient's arrival in the Emergency Department (ED) and possibly performing a CT scan. With SOR, it means clinical observation of patients with CT signs of suspected MBI (i.e., extraluminal air, bowel wall thickening, arterial vessel extravasation, mesenteric stranding, bowel wall discontinuity, reduced bowel wall enhancement, free fluid without solid organ injuries, and mesenteric hematoma) and selective deferred surgical exploration only in patients with clinical deterioration after repeated CT scan with worsened radiological signs. The term DOR means surgical exploration for MBI after a delay from patient's arrival in the ED, failed non-operative management, or delayed diagnosis. No language restrictions have been applied, and either prospective or retrospective comparative cohort studies were initially selected to maximize the number of patients. On the other hand, the studies considering only penetrating trauma or only pediatric patients were excluded from the research. The eligibility for study inclusion into the meta-analysis and study quality assessment were performed independently by two authors, namely PF and MT. Study data were extracted into standard forms independently by the mentioned authors. Discrepancies between the two investigators were resolved by discussing and evaluating the question with other investigators. Studies were divided into two groups, including those analyzing patients with proven MBI comparing EOR and DOR (sub-grouped according to the delayed cut-off used to distinguish "early" and "deferred" surgical intervention in each study: $<12 \mathrm{~h}$ vs $\geq 12 \mathrm{~h}$ ) and those focusing on patients with CT signs of suspected MBI comparing EOR and SOR and comparing EOR and DOR (subgrouped according to the presence of high risk or low-risk CT signs for suspected MBI (Table 1)).

The primary outcomes for the meta-analysis were mortality, complication rate, length of stay (LOS), the necessity of stoma formation, necessity of bowel resection, failure rate, and non-therapeutic surgical exploration rate (negative surgical exploration or findings which do not require surgical repair). The outcome "failure" means non-therapeutic surgical exploration for EOR and the necessity of surgical exploration during observation for SOR.

\subsection{Risk of bias assessment}

Data quality of studies was assessed using the Methodological Index for Non-Randomized Studies (MINORS) (18). By considering 12 items (8 for noncomparative and 4 for comparative studies) the total score was calculated by summing the values attributed as follows: $0=$ not reported, $1=$ reported but inadequate, 2=reported and adequate. Global ideal scores for non-comparative and comparative studies were obtained at 16 and 24, respectively.

\subsection{Statistical analysis}

Data from the individual eligible studies were

\begin{tabular}{lc}
\hline $\begin{array}{l}\text { Table 1. High-risk and low-risk computed tomography signs } \\
\text { for suspected mesenteric and bowel injuries (12) }\end{array}$ \\
\hline $\begin{array}{l}\text { High-risk computed } \\
\text { tomography signs }\end{array}$ & $\begin{array}{c}\text { Low-risk computed tomography } \\
\text { signs }\end{array}$ \\
\hline $\begin{array}{l}\text { Pneumoperitoneum } \\
\text { Active mesenteric } \\
\text { bleeding }\end{array}$ & Bowel wall thickening \\
& Mesenteric stranding \\
& Bowel wall discontinuity \\
& $\begin{array}{c}\text { Reduced bowel wall enhancement } \\
\text { Free fluid without solid organ } \\
\text { injuries }\end{array}$ \\
& Mesenteric hematoma \\
\hline
\end{tabular}


entered into a spreadsheet for further analysis. The Review Manager software (Version 5.3., Copenhagen: The Nordic Cochrane Centre, The Cochrane Collaboration, 2011) was used to perform the statistical analysis. Risk Ratio (RR) was calculated for discrete variables (19) and Mean Difference (MD) was assessed for continuous variables. The random and fixed-effects models were used to calculate the outcomes. Heterogeneity amongst the trials was determined employing the Cochrane $Q$ value and quantified using the $\mathrm{I}^{2}$ inconsistency test.

\section{Results}

Finally, 17 studies fulfilled the inclusion criteria and were included in the meta-analysis, which were all observational studies, including 15 retrospective and 2 prospective studies (publication dates 19982019) (Figure 1).

Among these studies, ten studies focused on patients with proven MBI and seven studies on patients with CT signs of suspected MBI. There were a total of 2,702 patients, including 2,119 cases with proven MBI 11,402 in the EOR group and 717 in the DOR group) (Table 2) and 583 subjects with CT signs of suspected MBI (173 in the EOR group and 410 in SOR group) (Table 3). The inclusion and exclusion criteria, considered CT signs, mean scores age and injury severity score, and the cut-off delay of each study are reported in Table 1-2. For studies on patients with proven MBI, the range of delay varied

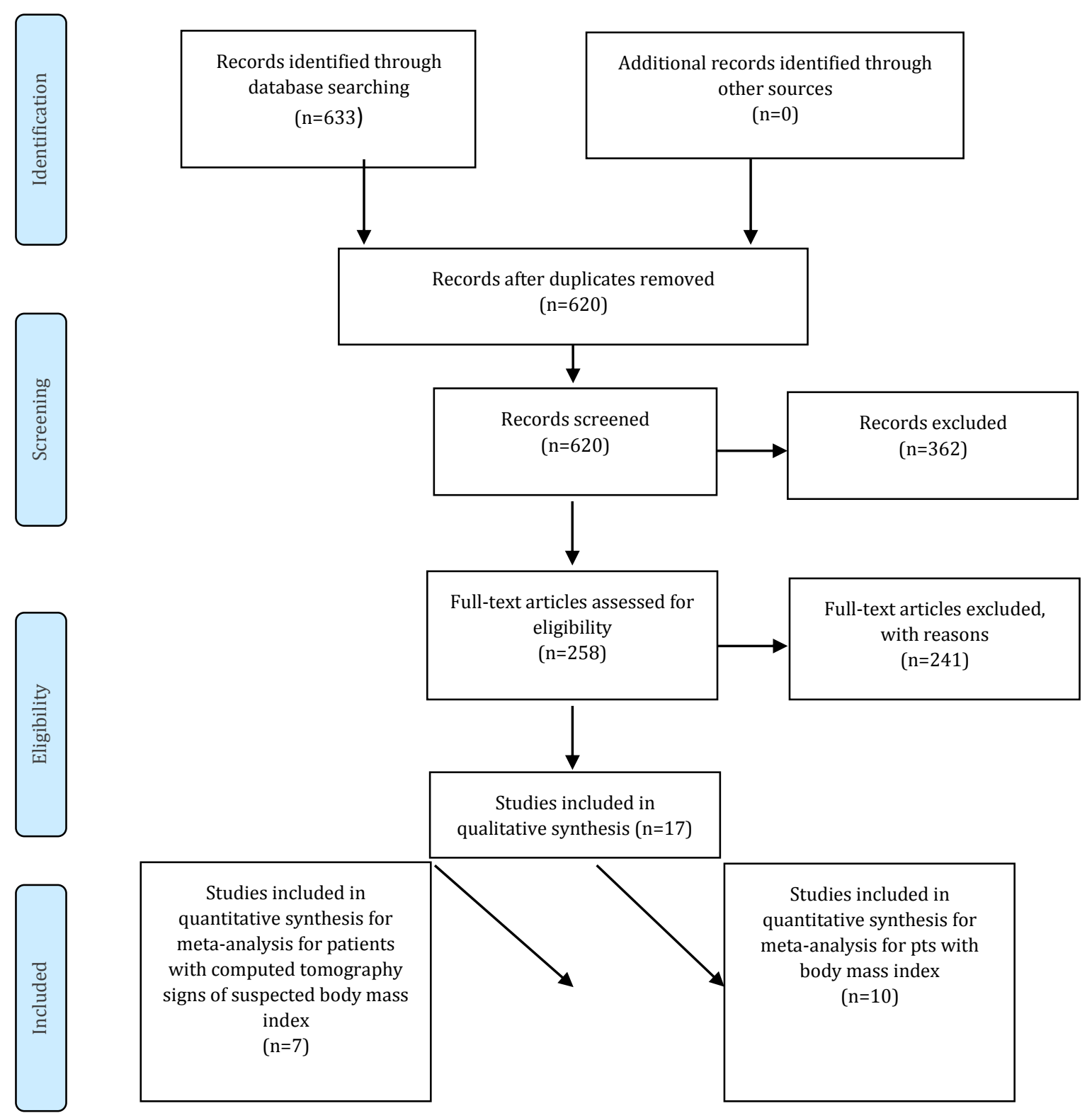

Figure 1. PRISMA flow diagram 


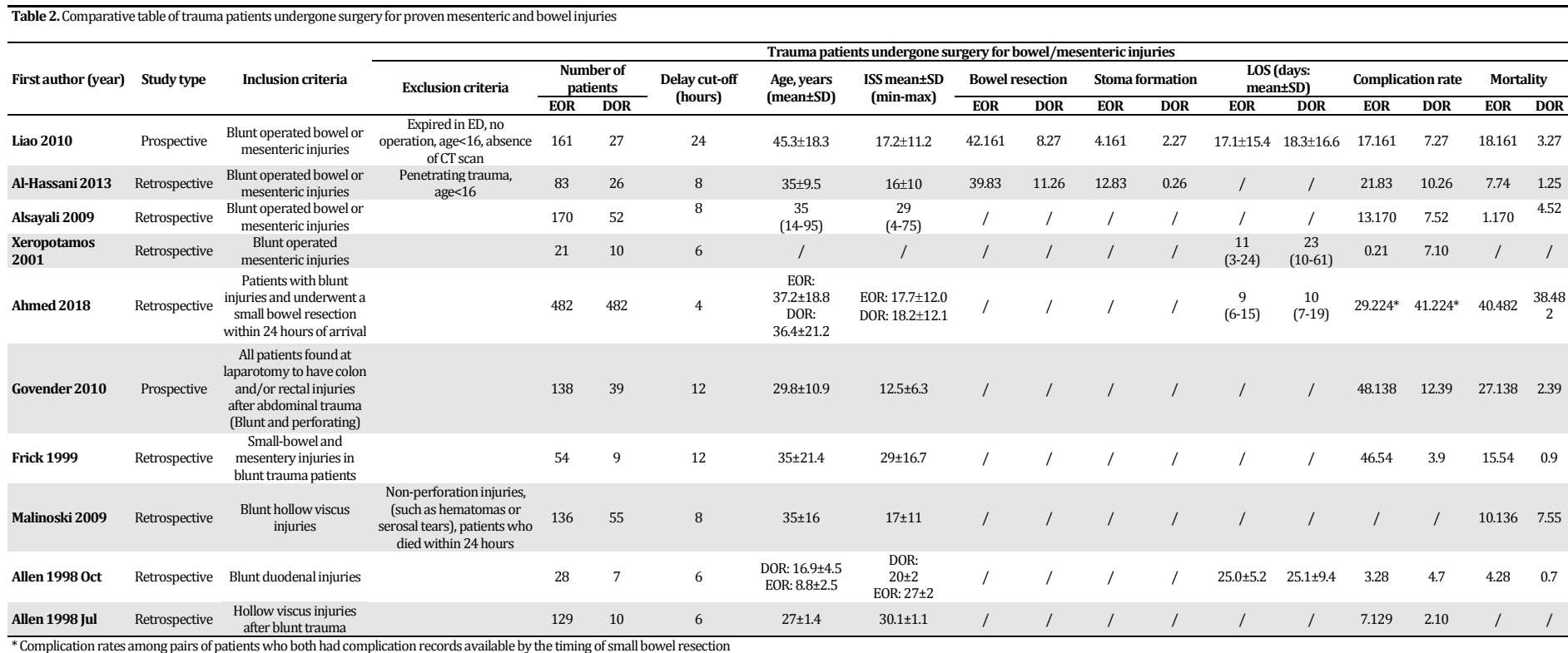

* Complication rates among pairs of patients who both had complication records available by the timing of small bowel resection

LOS: Length of Stay: ISS: Injury severity score; EOR: Early surgical exploration; DOR: Delayed surgical exploration; ED: Emergency department: CT: Computed tomography

Table 3. Comparative table of trauma patients with computed tomography signs of suspected mesenteric and bowel injuries

\begin{tabular}{|c|c|c|c|c|c|c|c|c|c|c|c|c|c|c|c|c|c|c|c|c|c|}
\hline \multirow{3}{*}{$\begin{array}{l}\text { First } \\
\text { author } \\
\text { (year) }\end{array}$} & \multirow[b]{3}{*}{ Study type } & \multirow[b]{3}{*}{$\begin{array}{l}\text { computed tomography } \\
\text { signs }\end{array}$} & \multirow[b]{3}{*}{ Exclusion criteria } & \multirow[b]{3}{*}{$\begin{array}{c}\text { Bowel/ } \\
\text { mesentery }\end{array}$} & \multirow{2}{*}{\multicolumn{2}{|c|}{ 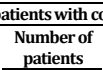 }} & \multirow{3}{*}{$\begin{array}{c}\text { omputed to } \\
\text { Age, } \\
\text { years } \\
\text { (mean } \pm S \\
\text { D) }\end{array}$} & \multirow{3}{*}{$\begin{array}{c}\text { omograph } \\
\text { ISS } \\
\text { mean } \pm S \\
D(\min - \\
\text { max) }\end{array}$} & \multirow{3}{*}{$\begin{array}{l}\text { y signs of susp } \\
\text { Nontherape } \\
\text { utic } \\
\text { EOR/total } \\
\text { EOR(EOR } \\
\text { failure) }\end{array}$} & \multirow{3}{*}{$\begin{array}{l}\text { pected mesentery } / \mathrm{h} \\
\text { Delayed } \\
\text { laparotomy/Obse } \\
\text { rved } \\
\text { patients(SOR } \\
\text { failure) }\end{array}$} & \multirow{3}{*}{$\begin{array}{l}\text { Nollow viscus } \\
\text { Nontherape } \\
\text { utic } \\
\text { DOR/total } \\
\text { DOR(DOR } \\
\text { failure) }\end{array}$} & \multirow[b]{3}{*}{$\begin{array}{c}\text { Delay(days; } \\
\text { mean } \pm S D \text { ) }\end{array}$} & \multirow{2}{*}{\multicolumn{3}{|c|}{ LOS (days: mean $\pm S D$ ) }} & \multirow{2}{*}{\multicolumn{3}{|c|}{ Complication rate }} & \multirow{2}{*}{\multicolumn{3}{|c|}{ Mortality }} \\
\hline & & & & & & & & & & & & & & & & & & & & & \\
\hline & & & & & EOR & SOR & & & & & & & IOR & SOR & DOR & IOR & SOR & DOR & IOR & SOR & DOR \\
\hline $\begin{array}{l}\text { Lannes } \\
2019\end{array}$ & Retrospective & $\begin{array}{c}\text { Hemoperitoneum, } \\
\text { mesenteric } \\
\text { pneumoperitoneum, bowel } \\
\text { wall thickening, arterial } \\
\text { mesenteric vessel } \\
\text { extravasation, mesenteric } \\
\text { stranding, bowel wall } \\
\text { discontinuity, reduced } \\
\text { bowel wall enhancement, } \\
\text { and anterior abdominal wall } \\
\text { injury }\end{array}$ & Penetrating trauma & $\mathrm{B}+\mathrm{M}$ & 22 & 62 & $43(8-84)$ & $\begin{array}{l}27.2 \\
(5.2- \\
18.3)\end{array}$ & 3.22 & 18.62 & 3.18 & $\begin{array}{l}2.5 \text { days } \pm 2 \\
\text { (range } 0-7 \text { ) }\end{array}$ & 22 & 40 & 53 & 3.22 & 8.62 & 6.18 & 1.22 & 7.62 & 1.18 \\
\hline Park 2018 & Retrospective & $\begin{array}{l}\text { Mesenteric hematoma, } \\
\text { mesenteric fat infiltration, } \\
\text { bowel wall thickening, or } \\
\text { free fluid in the peritoneal } \\
\text { cavity }\end{array}$ & $\begin{array}{c}\text { Patients who required } \\
\text { emergency surgery for } \\
\text { large } \\
\text { pneumoperitoneum, } \\
\text { bowelischemia, other } \\
\text { complicated solid organ } \\
\text { injuries, or large } \\
\text { extravasation of contrast } \\
\text { from bowel or } \\
\text { mesenteric injury by CT } \\
\text { scan at the admission, } \\
\text { hemodynamical } \\
\text { instability }\end{array}$ & $\mathrm{B}+\mathrm{M}$ & 35 & 42 & $\begin{array}{l}41+15 \\
(17-78)\end{array}$ & $13 \pm 4$ & 13.35 & 18.42 & 3.18 & $\begin{array}{l}3 \pm 2 \text { days (range, } \\
2-9 \text { days) }\end{array}$ & $15 \pm 14$ & $18 \pm 23$ & I & 14.35 & 7.42 & 7.18 & I & I & / \\
\hline $\begin{array}{l}\text { McNutt } \\
2014\end{array}$ & Retrospective & & $\begin{array}{l}\text { Lack of abdominal CT } \\
\text { scan, abdominal } \\
\text { operation before CT } \\
\text { scan, off-protocol CT } \\
\text { scan, and CT Grade } 5 \\
\text { injury (active } \\
\text { extravasation or } \\
\text { pneumoperitoneum), } \\
\text { hemodinamycal } \\
\text { instability }\end{array}$ & $\mathrm{B}+\mathrm{M}$ & 43 & 67 & $42(23-55)$ & $19(9-34)$ & 4.43 & 17.67 & 1.17 & $\begin{array}{c}18.8 \text { hours (range, } \\
5.2 \text { hours to } 8.2 \\
\text { days) }\end{array}$ & $14(8-24)$ & $\begin{array}{c}10 \\
(4-23)\end{array}$ & $17(9-23)$ & 15.43 & 13.67 & 6.17 & 3.43 & 1.67 & 1.17 \\
\hline Bège 2014 & Retrospective & $\begin{array}{l}\text { Bowel wall discontinuity, } \\
\text { bowel wall thickening, } \\
\text { abnormal bowel wall } \\
\text { enhancement, and } \\
\text { extraluminal air, infiltration, } \\
\text { haematoma, intravenous } \\
\text { contrastextravasation, } \\
\text { mesenteric vascular } \\
\text { beading appearance, and } \\
\text { occlusion of a mesenteric } \\
\text { vessel }\end{array}$ & $\begin{array}{l}\text { Patients who underwent } \\
\text { abdominal surgery } \\
\text { without an initialCT } \\
\text { scan }\end{array}$ & $\mathrm{B}+\mathrm{M}$ & 11 & 32 & $43(15-82)$ & $20(4-50)$ & 1.11 & 12.32 & 0.12 & $3(1-21)$ & $20(8-26)$ & 21 & $32(2-66)$ & 3.11 & $\%$ & 9.12 & 2.11 & 2.32 & 2.12 \\
\hline $\begin{array}{l}\text { Marek } \\
2014\end{array}$ & Retrospective & Freeintraabdominal air & & B & 38 & 36 & 38.9 & 21.9 & 10.38 & 2.36 & 1.2 & I & I & I & I & I & I & I & / & I & I \\
\hline Jost 2017 & Retrospective & $\begin{array}{l}\text { Intraperitoneal free fluid } \\
\text { withoutsolid organ injuries }\end{array}$ & $\begin{array}{c}\text { Hemodynamical } \\
\text { instability, contiguous } \\
\text { solid organ injury, } \\
\text { obvious extravasationof } \\
\text { oral contrast from a HVI } \\
\text { or other obvious hollow } \\
\text { viscus injury, observed } \\
\text { mesenteric chemorrhage, } \\
\text { and intraperitoneal } \\
\text { bladder ruptures, pts } \\
\text { dead in the first } 24 \text { hour }\end{array}$ & $M+B$ & 14 & 25 & $34(23-50)$ & $\begin{array}{l}25(18- \\
32)\end{array}$ & 3.14 & 7.25 & 3.7 & & $9(4-14)$ & $\begin{array}{l}17.8 \\
(5.5- \\
43)\end{array}$ & $\begin{array}{c}35(14.5- \\
43)\end{array}$ & 12.14 & 15.25 & 7.7 & I & I & I \\
\hline $\begin{array}{l}\text { Gonser- } \\
\text { Hafertepen } \\
2014\end{array}$ & Retrospective & $\begin{array}{l}\text { Patients with free fluid and } \\
\text { no sign of solid organ } \\
\text { injuries or hollow viscus } \\
\text { injury (defined as bowel } \\
\text { wall thickening contrast } \\
\text { extravasation, or } \\
\text { extraluminal air) }\end{array}$ & $\begin{array}{c}\text { Bowel wall thickening, } \\
\text { contrast extravasation, } \\
\text { or extraluminnal air, } \\
\text { hemodynamically } \\
\text { unstable, peritonitis, } \\
\text { traumatic abdominal } \\
\text { wall hernia, solid organ } \\
\text { injuries } \\
\end{array}$ & $M+B$ & 10 & 146 & 35 & 14 & 1.10 & 4.146 & 0.4 & I & l & I & I & I & I & I & I & I & / \\
\hline
\end{tabular}




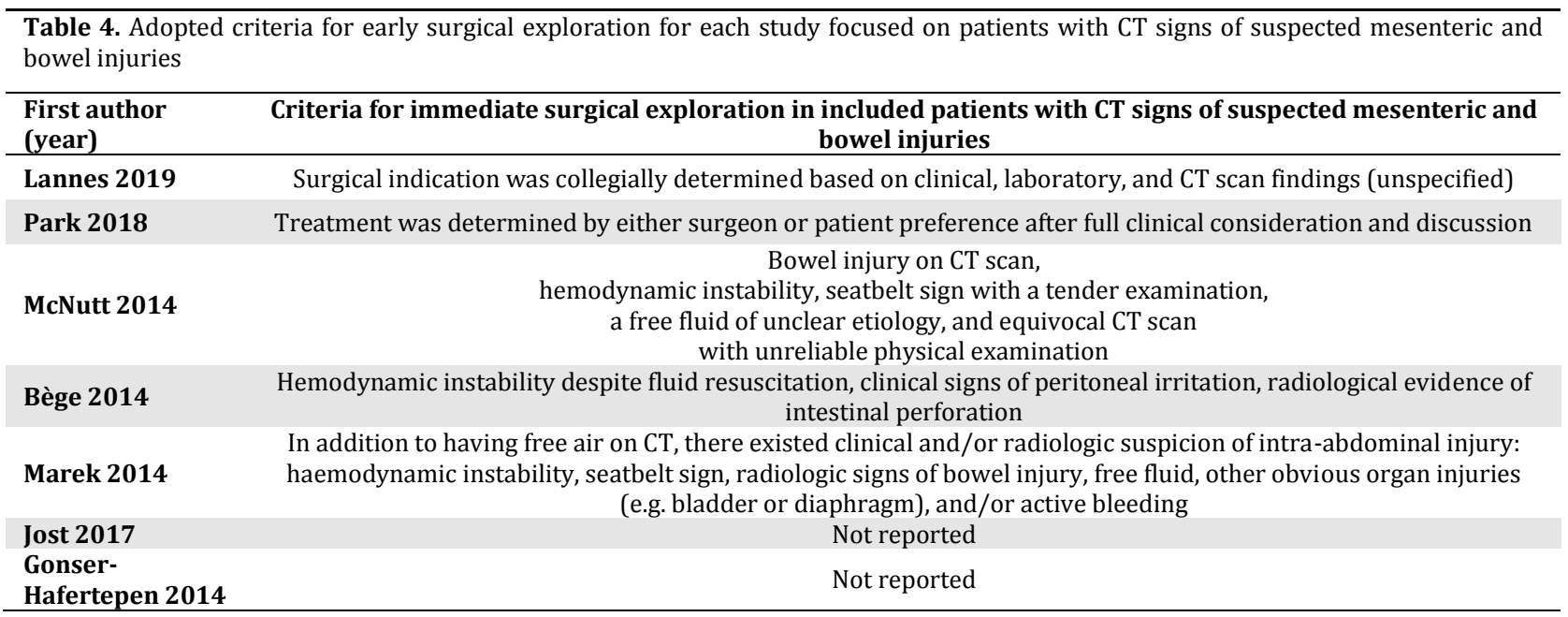

from 4-24 h. For studies on patients with CT signs suspected for MBI, the adopted criteria for EOR for each study are reported in Table 4, and for those undergone a DOR, the range of the mean delay varied from $18 \mathrm{~h}$ to 3 days (Table 3 ).

\subsection{Quality of trials}

There was good agreement between the reviewers (i.e., PF and MT) about the eligibility and quality of the studies. Table 5 demonstrates the quality of the included studies. All studies, although not randomized, were considered to be at acceptable risk of bias in the important domains.
3.2. Meta-analysis of studies focusing on trauma patients undergone surgery for proven MBI comparing EOR and DOR

-Mortality

The mortality rate for EOR versus DOR was reported in seven studies $(14,20-26)$. Overall, 1,243 and 696 patients received EOR and DOR, respectively. There was no statistical heterogeneity between studies (Figure 2A), and in the fixed-effects model, the mortality rate was not significantly different between EOR and DOR (RR=1.12, 95\% $\mathrm{CI}=0.81-1.55, \mathrm{P}=0.48)$.

\begin{tabular}{|c|c|c|c|c|c|c|c|c|c|c|c|c|c|c|}
\hline & \multirow[b]{2}{*}{$\begin{array}{l}\text { Study } \\
\text { (Ref.) } \\
\text { Year } \\
\end{array}$} & \multicolumn{8}{|c|}{ Quality evaluation criteria } & \multicolumn{5}{|c|}{ Additional criteria in comparative studies } \\
\hline & & $\begin{array}{c}\text { Clear } \\
\text { stated } \\
\text { aim }\end{array}$ & $\begin{array}{l}\text { Inclusion of } \\
\text { consecutive } \\
\text { patients }\end{array}$ & $\begin{array}{l}\text { Prospective } \\
\text { data } \\
\text { collection }\end{array}$ & $\begin{array}{c}\text { Endpoints } \\
\text { appropriat } \\
\text { e to the } \\
\text { study aim } \\
\end{array}$ & $\begin{array}{c}\text { Unbiased } \\
\text { assessmen } \\
\text { t of study } \\
\text { end-point } \\
\end{array}$ & $\begin{array}{l}\text { Appropria } \\
\text { te follow- } \\
\text { up period }\end{array}$ & $\begin{array}{c}\text { Loss to } \\
\text { follow- } \\
\text { up less } \\
\text { than 5\% } \\
\end{array}$ & $\begin{array}{c}\text { Prospective } \\
\text { calculation } \\
\text { of the study } \\
\text { size } \\
\end{array}$ & $\begin{array}{l}\text { Adequate } \\
\text { control } \\
\text { group }\end{array}$ & $\begin{array}{l}\text { Contempor } \\
\text { ary groups }\end{array}$ & $\begin{array}{c}\text { Baseline } \\
\text { equivalence }\end{array}$ & $\begin{array}{c}\text { Adequate } \\
\text { statistical } \\
\text { analysis }\end{array}$ & Total \\
\hline 1 & $\begin{array}{l}\text { Lannes } \\
2019 \text { [9] }\end{array}$ & 2 & 2 & 0 & 2 & 2 & 2 & 0 & 0 & 2 & 2 & 0 & 2 & 16 \\
\hline 2 & $\begin{array}{l}\text { Park } 2018 \\
{[10]}\end{array}$ & 2 & 2 & 0 & 2 & 2 & 2 & 0 & 0 & 2 & 2 & 2 & 2 & 18 \\
\hline 3 & $\begin{array}{l}\text { McNutt } \\
2014 \text { [7] }\end{array}$ & 2 & 2 & 0 & 2 & 2 & 2 & 0 & 0 & 2 & 2 & 1 & 2 & 17 \\
\hline 4 & $\begin{array}{l}\text { Bège } 2014 \\
\text { [11] }\end{array}$ & 2 & 2 & 0 & 2 & 2 & 2 & 0 & 0 & 2 & 2 & 2 & 2 & 18 \\
\hline 5 & $\begin{array}{l}\text { Marek } \\
2014 \text { [15] }\end{array}$ & 2 & 2 & 0 & 2 & 2 & 2 & 0 & 0 & 2 & 2 & 2 & 2 & 18 \\
\hline 6 & $\begin{array}{l}\text { Jost } 2017 \\
{[12]}\end{array}$ & 2 & 2 & 0 & 2 & 2 & 2 & 0 & 0 & 2 & 2 & 1 & 2 & 17 \\
\hline 7 & $\begin{array}{l}\text { Gonser- } \\
\text { Hafertepen } \\
2014 \text { [16] }\end{array}$ & 2 & 2 & 0 & 2 & 2 & 2 & 2 & 0 & 2 & 2 & 2 & 2 & 18 \\
\hline 8 & $\begin{array}{l}\text { Liao } 2010 \\
{[26]}\end{array}$ & 2 & 2 & 2 & 2 & 2 & 2 & 0 & 0 & 2 & 2 & 2 & 2 & 20 \\
\hline 9 & $\begin{array}{l}\text { Al-Hassani } \\
2013[21]\end{array}$ & 2 & 2 & 0 & 2 & 2 & 2 & 0 & 0 & 2 & 2 & 2 & 2 & 18 \\
\hline 10 & $\begin{array}{l}\text { Alsayali } \\
2009[23]\end{array}$ & 2 & 2 & 0 & 2 & 2 & 2 & 0 & 0 & 2 & 2 & 0 & 0 & 14 \\
\hline 11 & $\begin{array}{l}\text { Xerepotam } \\
\text { os 2001 } \\
{[28]}\end{array}$ & 2 & 2 & 0 & 2 & 2 & 2 & 0 & 0 & 2 & 2 & 0 & 2 & 16 \\
\hline 12 & $\begin{array}{l}\text { Ahmed } \\
2018 \text { [20] }\end{array}$ & 2 & 2 & 0 & 2 & 2 & 2 & 0 & 0 & 2 & 2 & 2 & 2 & 18 \\
\hline 13 & $\begin{array}{l}\text { Govender } \\
2010[25]\end{array}$ & 2 & 2 & 2 & 2 & 2 & 2 & 0 & 0 & 1 & 2 & 0 & 2 & 17 \\
\hline 14 & $\begin{array}{l}\text { Frick } 1999 \\
{[24]}\end{array}$ & 2 & 2 & 0 & 2 & 2 & 2 & 0 & 0 & 2 & 2 & 0 & 2 & 16 \\
\hline 15 & $\begin{array}{l}\text { Malinoski } \\
2009[14]\end{array}$ & 2 & 2 & 0 & 2 & 2 & 2 & 0 & 0 & 0 & 2 & 0 & 2 & 14 \\
\hline 16 & $\begin{array}{l}\text { Allen } 1998 \\
\text { Oct [22] }\end{array}$ & 2 & 2 & 0 & 2 & 2 & 2 & 0 & 0 & 2 & 2 & 2 & 2 & 18 \\
\hline 17 & $\begin{array}{l}\text { Allen } 1998 \\
\text { Jul [27] }\end{array}$ & 2 & 2 & 0 & 1 & 2 & 2 & 0 & 0 & 1 & 2 & 0 & 2 & 14 \\
\hline
\end{tabular}




\section{-Complication rate}

The complication rate for EOR versus DOR was reported in nine studies (20-28). Overall, 1,008 and 404 patients received EOR and DOR, respectively. Among the studied pieces of research, 6 (20-23, 27, 28) and 3 studies (24-26) used a cut-off (to distinguish "early" and "deferred" surgical intervention) lower and higher than $12 \mathrm{~h}$, respectively. Considering all studies, there was statistical heterogeneity between studies (Figure 2B), and in the random-effects model, the complication rate was significantly lower in EOR ( $\mathrm{RR}=0.61,95 \% \mathrm{CI}=0.38-0.98, \mathrm{P}=0.04$ ). Considering the studies with a delay cut-off higher or equal to 12 h (i.e., 12 h or 24 h), statistical heterogeneity was observed between studies, and in the random-effects model, the complication rate was not significantly different between EOR and DOR (RR=1.03, 95\% $\mathrm{CI}=0.41-2.58, \mathrm{P}=0.95)$. Focusing on studies with a delay cut-off lower than 12 h (i.e., 4 h, 6 h, or 8 h) there was no statistical heterogeneity between studies, and both in the random-effects model and in the fixed-effects model, the complication rate was significantly lower in EOR, compared to DOR (RR=0.47, 95\% CI=0.29-0.79, $\mathrm{P}=0.004$ )

\section{-Length of stay}

Length of stay was reported in 4 studies (20, $22,26,28)$ for EOR versus DOR. Overall, 434 and 268 patients respectively received EOR and DOR. There was no statistical heterogeneity between studies (Figure 2C), and in the fixed-effects model, the LOS was significantly lower in EOR, compared to DOR (MD $=-1.04,95 \% \mathrm{CI}=-1.53--0.54$, $\mathrm{P}<0.0001$ ).

\section{-Necessity of bowel resection}

The necessity of bowel resection was reported in 2 studies $(21,26)$ for EOR versus DOR. Overall, 244 and 53 patients received EOR and DOR, respectively. No statistical heterogeneity was found between studies (Figure 2D), and in the fixed-effects model, the necessity of bowel resection was not significantly different between EOR and DOR (RR=1.01, 95\% $\mathrm{CI}=0.68-1.50, \mathrm{P}=0.97)$.

\section{-Stoma formation}

Stoma formation rate was reported in 2 studies $(21,26)$ for EOR versus DOR. Overall, 244 and 53 patients received EOR and DOR, respectively. There was statistical heterogeneity between studies (Figure 2E), and in the random-effects model, the stoma formation rate was not significantly different between EOR and DOR $(\mathrm{RR}=1.41,95 \% \mathrm{CI}=0.04$ 51.30, $\mathrm{P}=0.85$ ).

\subsection{Meta-analysis of studies focusing on patients with CT-signs of suspected MBI comparing EOR and SOR - Failure}

The failure rate was reported in 7 studies $(7,9$ $12,15,16)$ for EOR versus SOR. Overall, 173 and 410 patients received EOR and SOR, respectively. In 4 studies $(7,10,12,16)$ the focus was on patients with low-risk CT signs of suspected MBI and in 3 studies $(9,11,15)$ on patients with highrisk CT signs. Considering all studies, there was statistical heterogeneity between studies (Figure $3 \mathrm{~A}$ ), and in the random-effects model, the failure rate was not significantly different between EOR and SOR ( $R R=0.82,95 \% \mathrm{CI}=0.43-1.55, \mathrm{P}=0.53)$. Focusing on studies on patients with low-risk CTsigns, there was no statistical heterogeneity between studies, and in the random-effects model, the failure rate was not significantly different between EOR and SOR (RR=0.76, 95\% CI=0.411.43, $\mathrm{P}=0.40$ ). Focusing on studies on patients with high-risk CT-signs, there was statistical heterogeneity between studies, and in the randomeffects model, the failure rate was not significantly different between EOR and SOR (RR=0.85, 95\% $\mathrm{CI}=0.15-4.70, \mathrm{P}=0.85$ ).

\section{-Mortality}

The mortality rate was reported in 3 studies $(7,9$,

11) for EOR versus SOR. Overall, 76 and 161 patients received EOR and SOR, respectively. In 1 study (7) the focus was on patients with low-risk CT signs of suspected MBI and in 2 studies $(9,11)$ on patients with high-risk CT signs. Considering all studies, there was no statistical heterogeneity between studies (Figure 3B), and in the fixed-

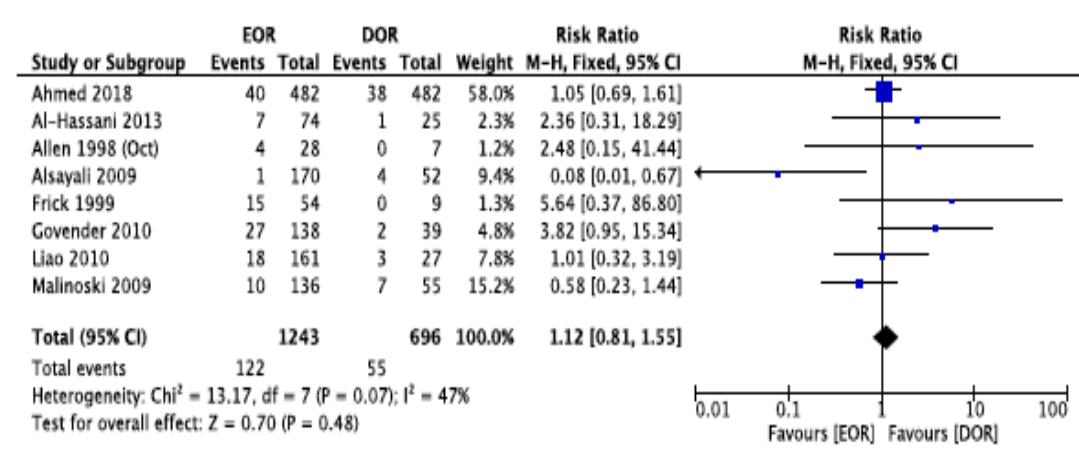

2 A. Mortality 


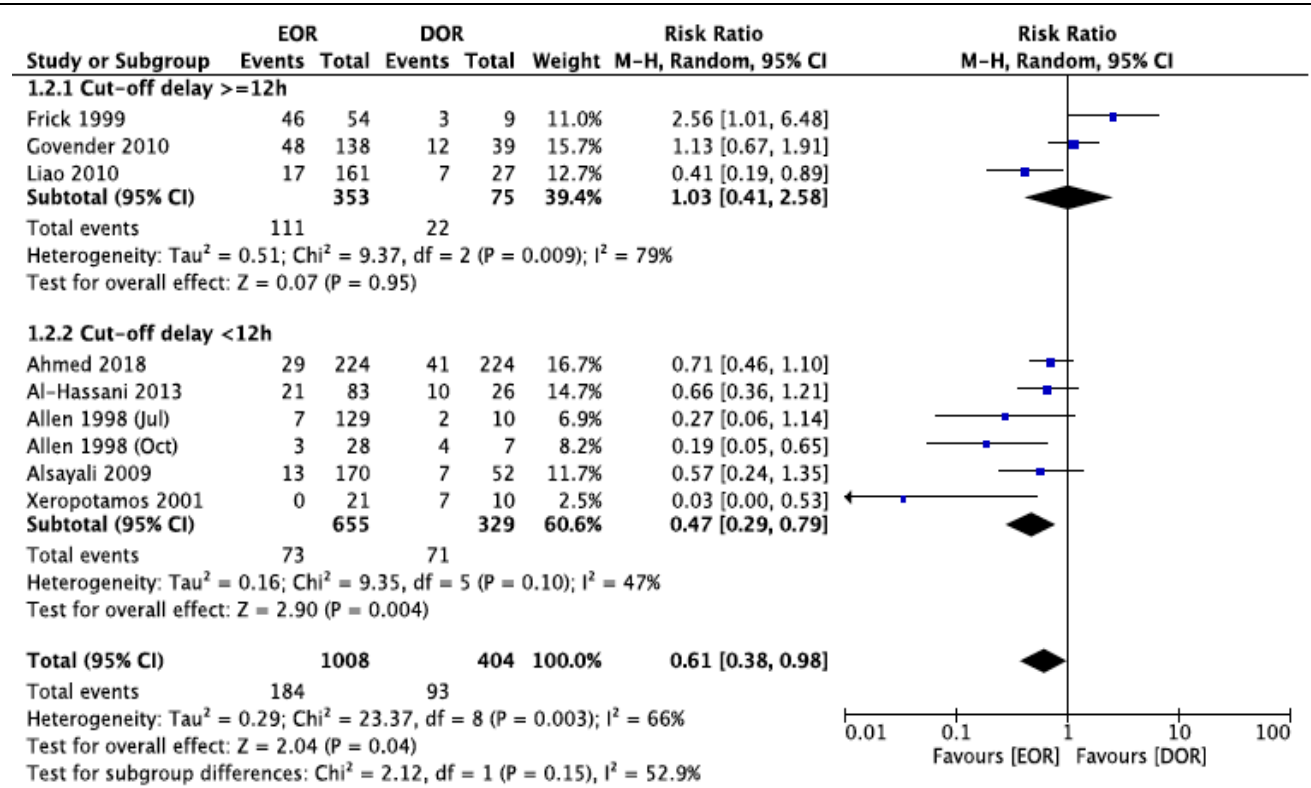

2 B. Complication

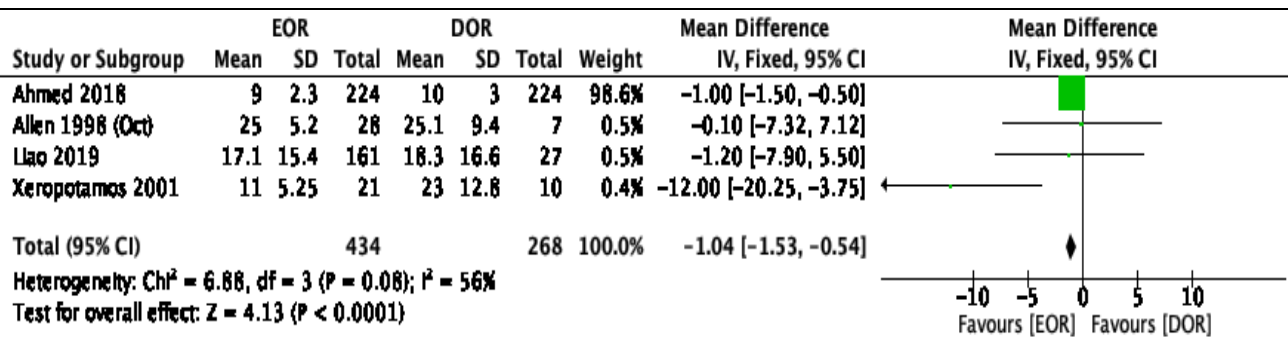

2 C. Length of stay

$\begin{array}{llll}\text { EOR } & \text { DOR } & \text { Risk Ratio Ratio }\end{array}$

Study or Subgroup Events Total Events Total Weight $\mathrm{M}-\mathrm{H}, \mathrm{Fixed}, 95 \% \mathrm{Cl} \quad \mathrm{M}-\mathrm{H}, \mathrm{Fixed}, 95 \% \mathrm{Cl}$

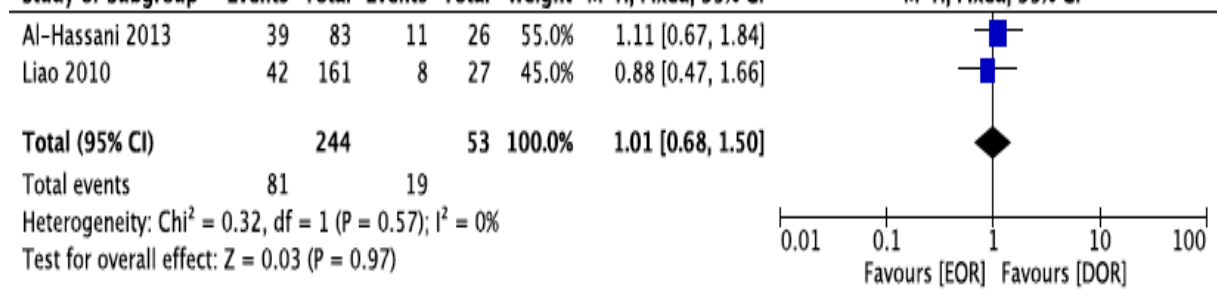

2 D. Necessity of bowel resection

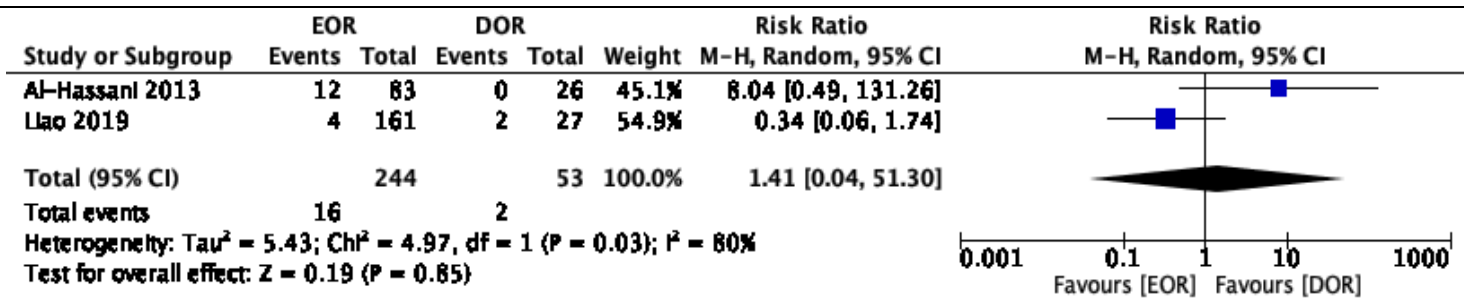

2 E. Stoma formation

Figure 2. Early Operative Room vs Deferred Operative Room in trauma patients undergone surgery for Bowel/Mesenteric Injuries

effects model, the mortality rate was not significantly different between EOR and SOR $(\mathrm{RR}=1.48,95 \% \mathrm{CI}=0.53-4.15, \mathrm{P}=0.45)$. Focusing on the study on patients with low-risk CT signs, the mortality rate was not significantly different between EOR and SOR $(\mathrm{RR}=4.67,95 \% \mathrm{CI}=0.50$ -
43.49, $\mathrm{P}=0.18)$. Considering the studies on patients with high-risk CT-signs, there was no statistical heterogeneity between studies, and in the fixedeffects model, the mortality rate was not significantly different between EOR and SOR $(\mathrm{RR}=0.95,95 \% \mathrm{CI}=0.27-3.32, \mathrm{P}=0.94)$. 


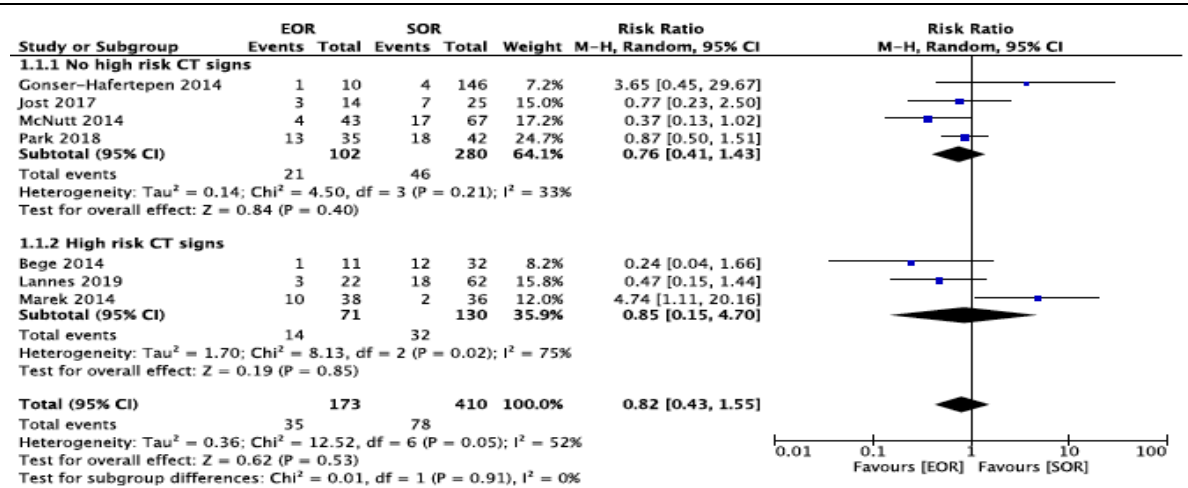

3A. Failure (Early Operative Room failure: non-therapeutic surgical intervention, Selective Operative Room failure: necessity of laparotomy during observation)

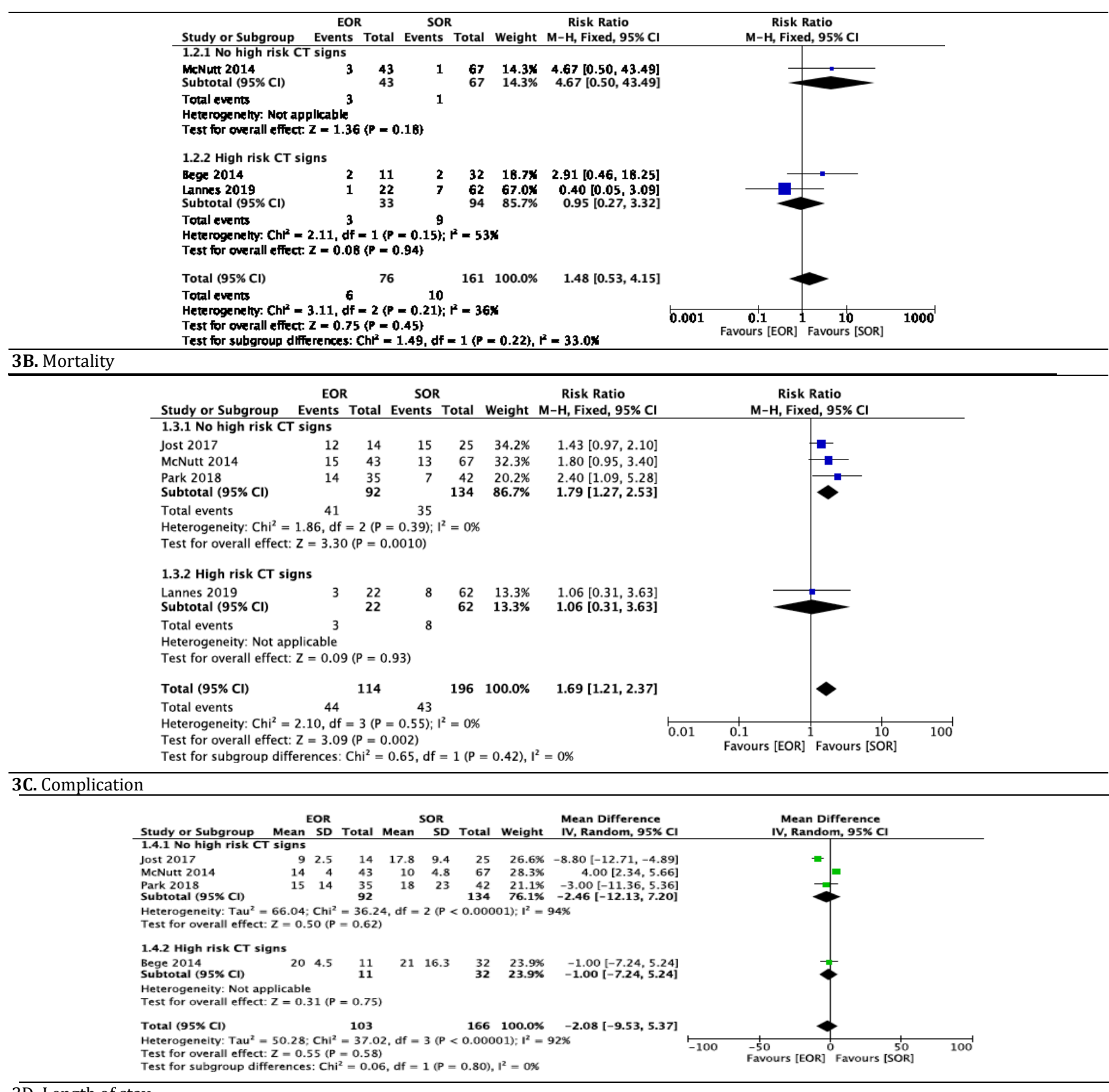

3D. Length of stay

Figure 3. Early Operative Room vs Selective Operative Room in trauma patients with computed tomography signs of suspected Bowel/Mesenteric Injuries (High-risk computed tomography signs: pneumoperitoneum and/or arterial mesenteric vessel contrast extravasation) 


\section{-Length of stay}

The length of stay was reported in 4 studies (7, 10-12) for EOR versus SOR. Overall, 103 and 166 patients received EOR and SOR, respectively. In 3 studies $(7,10,12)$, the focus was on patients with low-risk CT signs of suspected MBI, and in 1 study (11), on patients with high-risk CT signs. Considering all studies, there was statistical heterogeneity between studies (Figure 3D), and in the random-effects model, LOS was not significantly different between SOR and EOR (MD=-2.08, 95\% CI=-9.53-5.37, P=0.58). Focusing on the studies on patients with low-risk CT-signs, there was statistical heterogeneity between studies, and in the random-effects model, LOS was not significantly different between SOR and EOR (MD=-2.46, 95\% CI=-12.13-7.20, $\mathrm{P}=0.62)$. Considering the study on patients with high-risk CT signs, the complication rate was not significantly different between EOR and SOR $(\mathrm{MD}=-1.00,95 \% \mathrm{CI}=-7.24-5.24, \mathrm{P}=0.75)$.

\subsection{Meta-analysis of studies focusing on patients} undergone surgical exploration for CT-signs of suspected MBI comparing EOR and DOR

-Non-therapeutic surgical exploration

Non-therapeutic surgical exploration rate was reported in 7 studies $(7,9-12,15,16)$ for EOR versus DOR. Overall, 173 and 78 patients received EOR and DOR, respectively. The focus in 4 studies $(7,10,12$, 16) was on patients with low-risk CT signs of suspected MBI and in 3 studies $(9,11,15)$, on patients with high-risk CT signs. Considering all studies, there was no statistical heterogeneity between studies (Figure 4A), and in the fixed-effects model, the non-therapeutic surgical exploration rate was not significantly different between EOR and DOR ( $\mathrm{RR}=1.22,95 \% \mathrm{CI}=0.67-2.23, \mathrm{P}=0.51$ ). Focusing on studies on patients with low-risk CT-signs, there was no statistical heterogeneity between studies, and in the fixed-effects model, the non-therapeutic surgical intervention rate was not significantly different between EOR and DOR (RR=1.39, 95\% CI=0.66-2.93, $\mathrm{P}=0.38$ ). Focusing on studies on patients with highrisk CT signs, there was no statistical heterogeneity between studies, and in the fixed-effects model, the non-therapeutic surgical exploration rate was not significantly different between EOR and SOR $(\mathrm{RR}=0.93,95 \% \mathrm{CI}=0.34-2.55, \mathrm{P}=0.88)$.

\section{-Mortality}

The mortality rate was reported in 3 studies $(7,9$, 11) for EOR versus DOR. Overall, 76 and 47 patients received EOR and DOR, respectively. The focus of 1 study (7) was on patients with low-risk CT signs of suspected MBI and that of 2 studies $(9,11)$ on patients with high-risk CT signs. Considering all studies, there was no statistical heterogeneity between studies (Figure 4B), and in the fixed-effects model, the mortality rate was not significantly different between EOR and DOR (RR=1.05, 95\% $\mathrm{CI}=0.31-3.61, \mathrm{P}=0.93$ ). Focusing on the study on patients with low-risk CT signs, the mortality rate was not significantly different between EOR and DOR $(\mathrm{RR}=1.19,95 \% \mathrm{CI}=0.13-10.62, \mathrm{P}=0.88)$. Focusing on studies on patients with high-risk CT-signs, there was no statistical heterogeneity between studies, and in the fixed-effects model, the mortality rate was not significantly different between EOR and SOR $(\mathrm{RR}=0.99,95 \% \mathrm{CI}=0.22-4.38, \mathrm{P}=0.99)$.

\section{-Complication rate}

The complication rate was reported in 5 studies $(7,9-12)$ for EOR versus DOR. Overall, 125 and 72 patients received EOR and DOR, respectively. In 3 studies $(7,10,12)$, the focus was on patients with low-risk CT signs of suspected MBI, and in 2 studies $(9,11)$, on patients with high-risk CT signs. Considering all studies, there was no statistical heterogeneity between studies (Figure 4C), and in the fixed-effects model, the complication rate was not significantly different between EOR and DOR

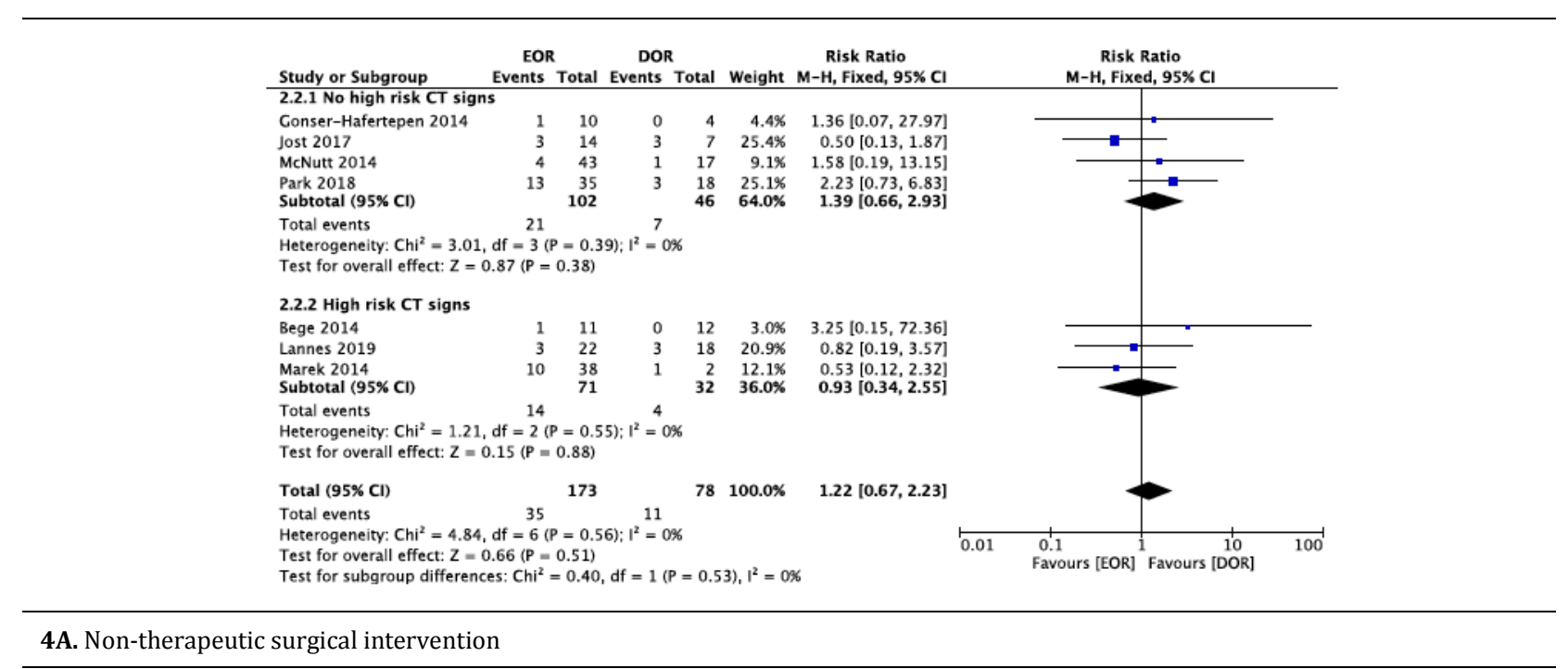



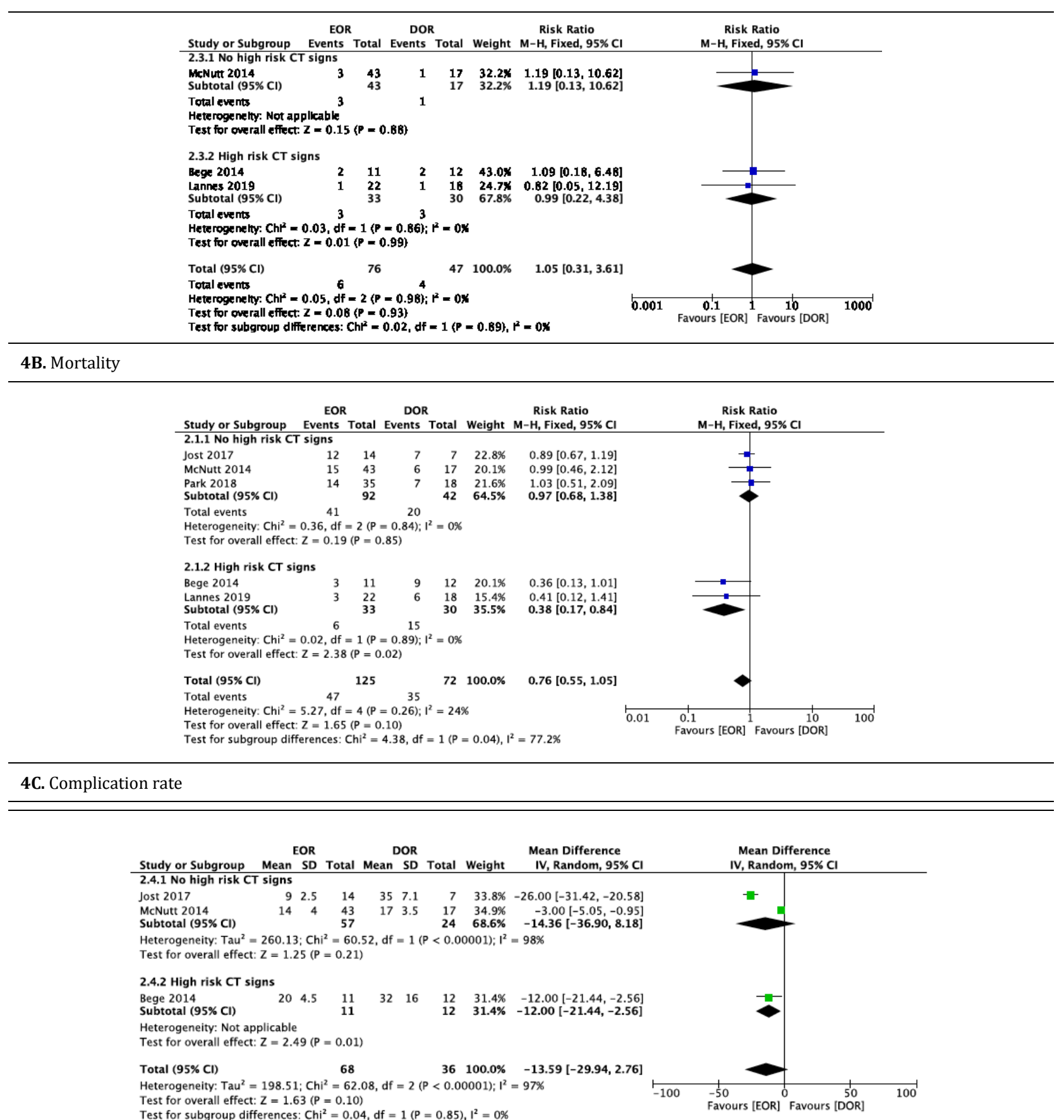

4D. Length of stay

Figure 4. Early Operating Room vs Deferred Operating Room in trauma patients undergone surgery for computed tomography signs of suspected Bowel/Mesenteric Injuries (High-risk computed tomography signs: pneumoperitoneum and/or arterial mesenteric vessel contrast extravasation)

( $R R=0.76,95 \%$ CI=0.55-1.05, P=0.10). Considering studies on patients with low-risk CT signs, the complication rate was not significantly different between EOR and DOR (RR=0.97, 95\% CI=0.681.38, $\mathrm{P}=0.85$ ). Focusing on studies on patients with high-risk CT-signs, there was no statistical heterogeneity between studies, and in the fixedeffects model, the complication rate was significantly lower in EOR, compared to DOR $(\mathrm{RR}=0.38,95 \% \mathrm{CI}=0.17-0.84, \mathrm{P}=0.02)$.

\section{-Length of stay}

Length of stay was reported in 3 studies $(7,11$, 12) for EOR versus DOR. Overall, 68 and 36 patients received EOR and DOR, respectively. In 2 studies (7, 12), the focus was on patients with low-risk CT signs of suspected MBI, and in 1 study (11), on patients with high-risk CT signs. Considering all studies, there was statistical heterogeneity between studies (Figure 4D), and in the random-effects model, LOS was not significantly different between 
EOR and DOR (MD=-13.59, 95\% CI=-29.94-2.76, $\mathrm{P}=0.10$ ). Focusing on studies on patients with lowrisk CT-signs, there was statistical heterogeneity between studies, and in the random-effects model, LOS was not significantly different between EOR and DOR (MD=-14.36, 95\% CI=-36.90-8.18-1.38, $\mathrm{P}=0.21$ ). Focusing on the study on patients with high-risk CT signs, LOS was significantly lower in EOR, compared to DOR (MD=-12.00, 95\% CI=21.44-2.56, $\mathrm{P}=0.01$ ).

\section{Conclusion}

It is well known that in trauma and emergency surgery setting, it is challenging to perform randomized controlled trials and obtain highquality data. It is even more difficult to focus on a such rare injury as MBI. Available data consist of observational studies and case series and, to the best of our knowledge, the present research was the first meta-analysis trying to collect and analyze the bodies of evidence available. First of all, available literature has not reached a definitive consensus about the influence of the delay in surgical intervention on the outcomes of a patient with proven traumatic MBI.

The results of the present study are consistent with those reported in most studies $(24,29,30)$, showing that the delay is not associated with higher mortality. The available evidence is even less clear regarding the effect of delay on morbidity. According to some authors, the delay did not lead to an increased complication rate $(24,31)$. However, the results of a recent review (29) showed that there were sufficient data to indicate higher morbidity, especially if surgical intervention was delayed for more than $24 \mathrm{~h}$. Morbidity in the early and delayed intervention groups varied from $14.1 \%-62 \%$ and $35 \%-63.6 \%$, respectively $(27,29$, 30,32 ).

Based on the findings of the present study, the heterogeneity of available results was probably due to the different delay cut-off points considered in the different studies to distinguish between "early" and "deferred" surgical intervention. To elaborate more, in the subgroup analysis, only considering studies with a delay cut-off lower than $12 \mathrm{~h}$ (i.e., $4 \mathrm{~h}, 6 \mathrm{~h}$, or $8 \mathrm{~h}$ ), the complication rate of patients with proven MBI was significantly lower in the EOR group. Probably, after $12 \mathrm{~h}$ from the patient's arrival, surgical intervention cannot bring the same benefits in terms of complications of an early one. Moreover, LOS was found to be shorter in the EOR group. No difference was revealed about the necessity of bowel resection and stoma formation between EOR and DOR; however, this result might have been obtained due to insufficient data on this topic.

The delay of the surgical intervention in patients with MBI aggravates patients' outcomes lead to the assumption that it would be advisable to perform surgical exploration in all patients with suspected MBI. Nevertheless, systematic surgical exploration for all hemodynamically stable patients with suspected bowel or mesenteric injury has led to a reported high rate of nontherapeutic laparotomy, up to $44 \%$ and $31 \%$ for suspected intestinal lesions and suspected mesenteric injuries, respectively (33). It has also resulted in the reported morbidity of a negative laparotomy ranging between $8 \%$ and $40 \%(8,34)$.

To compare the risks of EOR in all traumatic patients with CT signs of suspected BMI with the risks of clinical observation and SOR (in patients showing clinical deterioration or radiological signs aggravation), the present research analyzed failure rate, mortality rate, complication rate, and LOS in patients undergoing treatment with EOR vs SOR. Due to the presence of heterogeneity, a subgroup analysis was performed based on the presence or absence of high-risk CT signs, defined as the finding of pneumoperitoneum and/or arterial mesenteric vessel contrast extravasation at CT scan.

Free air is reported as a fairly reliable sign of bowel injury in patients with blunt abdominal trauma, with a specificity of $95 \%-100 \%(4,27)$; however, the reported sensitivity was only $30 \%$ $60 \%(4,27)$. Mesenteric extravasation has a reported sensitivity and specificity for acute mesenteric injury of $26 \%-77 \%$ and $40 \%-100 \%$, respectively. Other signs of suspected BMI are reported as extraluminal air, bowel wall thickening, arterial vessel extravasation, mesenteric stranding, bowel wall discontinuity, reduced bowel wall enhancement, free fluid without solid organ injuries, and mesenteric hematoma (7-16). Nonetheless, there have been no CT findings reported with both high sensitivity and specificity (28). In one study, multivariate analysis revealed CT findings of free air and mesenteric extravasation as the only risk factors for surgical intervention $(\mathrm{P}=0.0002$ and $\mathrm{P}=0.02$, respectively) (12).

According to the results of the present research, the failure rate (defined as performing a non-therapeutic surgical exploration in patients undergoing treatment with EOR and as the need for delayed surgical exploration in a patient undergoing SOR) and the LOS were not significantly different between EOR and SOR, neither in patients with high-risk CT signs nor in those without them. However, in the group of patients with low-risk CT signs, the complication rate was lower in patients undergoing clinical observation and SOR. Furthermore, the mortality rate seemed to be lower in the SOR group among patients with low-risk CT signs; nevertheless, it was not statistically significant. No differences 
were found in complication and mortality rates between EOR and SOR in patients with high-risk CT signs.

An analysis on patients with CT signs of suspected BMI, excluded patients with successful non-operative management and focused on patients undergoing surgical intervention, early (EOR) or deferred (DOR, for non-operative management failure). The non-therapeutic surgical exploration rate and the mortality rate were not significantly different between EOR and DOR, nor in patients with or without high risk CT signs. However, in the subgroup of patients with high risk CT signs, the complication rate and the LOS were lower than in patients undergoing early surgical exploration.

The major limitation of the present study was related to the low-quality of included studies, meaning that they were all observational studies, in almost all studies there were associated abdominal lesions which could be confounding factors, some studies involved both penetrating and blunt trauma patients, and each study considered different CT signs for suspected MBI. Moreover, since the included studies were performed between 1998 and 2019, the diagnostic performance of the CT could vary due to technological progress. Furthermore, the overlap of some patients in different study groups was possible. However, as already mentioned above, in this setting, higher-quality studies are highly difficult to be performed. Further studies are needed to be conducted to establish the role of the explorative laparoscopy and the diagnostic peritoneal lavage in the diagnosis of MBI, and that of novel techniques, such as angioembolization, in patients with arterial mesenteric bleeding.

In the light of previously reported findings, blunt trauma patients with CT signs of pneumoperitoneum and mesenteric active contrast bleeding should receive a surgical exploration as soon as possible, probably, in the authors' opinion, with an exploratory laparoscopy to minimize invasiveness in case of negative exploration or plan for subsequent therapeutic measures in case of injuries. Present data show that complications are reduced with surgical exploration within $12 \mathrm{~h}$. On the other hand, traumatic patients with low-risk CT signs of suspected MBI can receive clinical observation in an appropriate setting with the availability of continuous monitoring, a surgeon, an anesthetist, and an operating room $24 \mathrm{~h}$ a day. These patients should receive a clinical and/or radiological reevaluation within $12 \mathrm{~h}$, and in case of clinical or radiological aggravation, should receive a surgical exploration. This selective approach in patients without high-risk CT signs could reduce the complication rate without increasing mortality and LOS, compared to a systematic surgical intervention approach for all hemodynamically stable patients with suspected MBI. However, probably it would be better to maintain a low threshold for surgical exploration, possibly with an explorative laparoscopy, to minimize treatment delay.

\section{Acknowledgments}

None

\section{Footnotes}

Author's contributions: Study concept and design: P.F.; analysis and interpretation of data: P.F., and M.T.; drafting of the manuscript: P.F., M.T., C.Z., R.B., G.C., M.F.O., M.I.; critical revision of the manuscript for important intellectual content: M.C., F.C., E.G., V.A., L.A.; statistical analysis: P.F.

Ethical Approval: Not applicable

Informed Consent: Not applicable

Funding/Support: The authors received no specific funding for this work.

Conflicts of Interest: The authors declare no conflict of interest.

\section{References}

1. Coccolini F, Montori G, Catena F, Kluger Y, Biffl W, Moore EE, et al. Splenic trauma: WSES classification and guidelines for adult and pediatric patients. World J Emerg Surg. 2017;12:40. doi: 10.1186/s13017-017-0151-4. [PubMed: 28828034].

2. Coccolini F, Catena F, Moore EE, Ivatury R, Biffl W, Peitzman A, et al. WSES classification and guidelines for liver trauma. World J Emerg Surg. 2016;11:50. doi: 10.1186/s13017-0160105-2. [PubMed: 27766112].

3. Coccolini F, Moore EE, Kluger Y, Biffl W, Leppaniemi A, Matsumura $Y$, et al. Kidney and uro-trauma: WSES-AAST guidelines. World J Emerg Surg. 2019;14:54. doi: 10.1186/s13017-019-0274-x. [PubMed: 31827593].

4. Coccolini F, Kobayashi L, Kluger Y, Moore EE, Ansaloni L, Biffl $\mathrm{W}$,et al. Duodeno-pancreatic and extrahepatic biliary tree trauma: WSES-AAST guidelines. World J Emerg Surg. 2019;14:56. doi: 10.1186/s13017-019-0278-6. [PubMed: 31867050].

5. Fakhry SM, Allawi A, Ferguson PL, Michetti CP, Newcomb AB, Liu C, et al. Blunt small bowel perforation (SBP): An Eastern association for the surgery of trauma multicenter update 15 years later. J Trauma Acute Care Surg. 2019;86(4):642-50. doi: 10.1097/TA.0000000000002176. [PubMed: 30633100].

6. Watts DD, Fakhry SM, EAST Multi-Institutional HVI Research Group. Incidence of hollow viscus injury in blunt trauma: An analysis from 275,557 trauma admissions from the EAST multi-institutional trial. J Trauma. 2003;54(2):289-94. doi: 10.1097/01.TA.0000046261.06976.6A. [PubMed: 12579054].

7. McNutt MK, Chinapuvvula NR, Beckmann NM, Camp EA, Pommerening MJ, Laney RW, et al. Early surgical intervention for blunt bowel injury: the Bowel Injury Prediction Score (BIPS). J Trauma Acute Care Surg. 2015;78(1):105-11. doi: 10.1097/TA.0000000000000471. [PubMed: 25539210].

8. Coleman JJ, Zarzaur BL. Surgical management of abdominal trauma: hollow viscus injury. Surg Clin. North Am. 2017; 97(5):1107-17. doi: 10.1016/j.suc.2017.06.004. [PubMed: 28958360] 
9. Lannes F, Scemama U, Maignan A, Boyer L, Beyer-Berjot L, Berdah SV, et al. Value of early repeated abdominal CT in selective non-operative management for blunt bowel and mesenteric injury. Eur Radiol. 2019;29(11):5932-40. doi: 10.1007/s00330-019-06212-w. [PubMed: 31025065].

10. Park HC, Kim JW, Kim MJ, Lee BH. Outcomes of selective surgery in patients with suspected small bowel injury from blunt trauma. Ann Surg Treat Res. 2018;94(1):44-8. doi: 10.4174/astr.2018.94.1.44. [PubMed: 29333425].

11. Bège $T$, Chaumoître $K$, Léone $M$, Mancini J, Berdah SV, Brunet C. Blunt bowel and mesenteric injuries detected on CT scan: Who is really eligible for surgery? Eur J Trauma Emerg Surg. 2014;40(1):75-81. doi: 10.1007/s00068-013-0318-y. [PubMed: 26815780].

12. Jost E, Roberts DJ, Penney T, Brunet G, Ball CG, Kirkpatrick AW. Accuracy of clinical, laboratory, and computed tomography findings for identifying hollow viscus injury in blunt trauma patients with unexplained intraperitoneal free fluid without solid organ injury. Am J Surg. 2017; 213(5):874-80. doi: 10.1016/j.amjsurg.2017.03.016. [PubMed: 28351473].

13. Okishio Y, Ueda K, Nasu T, Kawashima S, Kunitatsu K, Kato S. Surgical intervention for blunt bowel and mesenteric injury: indications and time intervals. Eur J Trauma Emerg Surg. 2019. doi: 10.1007/s00068-019-01192-4. [PubMed: 31324939].

14. Malinoski DJ, Patel MS, Yakar DO, Green D, Qureshi F, Inaba K. A diagnostic delay of 5 hours increases the risk of death after blunt hollow viscus injury. J Trauma. 2010;69(1):84-7. doi: 10.1097/TA.0b013e3181db37f5. [PubMed: 20622582].

15. Marek AP, Deisler RF, Sutherland JB, Punjabi G, Portillo A, Krook J, et al. CT scan-detected pneumoperitoneum: An unreliable predictor of intra-abdominal injury in blunt trauma. Injury. 2014;45(1):116-21. doi: 10.1016/j.injury. 2013.08.017. [PubMed: 24041430].

16. Gonser-Hafertepen LN, Davis JW, Bilello JF, Ballow SL, Sue $\mathrm{LP}$, Cagle KM, et al. Isolated free fluid on abdominal computed tomography in blunt trauma: Watch and wait or operate? J Am Coll Surg. 2014;219(4):599-605. doi: 10.1016/j.jamcollsurg.2014.04.020. [PubMed: 25127510].

17. Cullinane DC, Jawa RS, Como JJ, Moore AE, Morris DS, Cheriyan J, et al. Management of penetrating intraperitoneal colon injuries: A meta-analysis and practice management guideline from the Eastern Association for the Surgery of Trauma. J Trauma Acute Care Surg. 2019;86(3):505-15. doi: 10.1097/TA.0000000000002146. [PubMed: 30789470].

18. Slim K, Nini E, Forestier D, Kwiatkowski F, Panis Y, Chipponi J. Methodological index for non-randomized studies (Minors): Development and validation of a new instrument. ANZ J Surg. 2003;73(9):712-6. doi: 10.1046/j.1445-2197. 2003.02748.x. [PubMed: 12956787].

19. Bonita R, Beaglehole R, Kjellström T. Basic epidemiology, 2nd edition: World Health Organization; 2006.

20. Ahmed N, Greenberg P. Examining the impact of small bowel resection procedure timing in patients with blunt traumatic injury: a propensity-matched analysis. Eur J Trauma Emerg Surg. 2020;46(3):615-20. doi: 10.1007/s00068-018-1056-y. [PubMed: 30683959].

21. Al-Hassani A, Tuma M, Mahmood I, Afifi I, Almadani A, El-
Menyar A, et al. Dilemma of blunt bowel injury: What are the factors affecting early diagnosis and outcomes. Am Surg. 2013;79(9):922-7. [PubMed: 24069992].

22. Allen GS, Moore FA, Cox Jr CS, Mehall JR, Duke JH. Delayed diagnosis of blunt duodenal injury: An avoidable complication. J Am Coll Surg. 1998;187(4):393-9. doi: 10.1016/s1072-7515(98)00205-1. [PubMed: 9783785].

23. Alsayali MM, Atkin C, Winnett J, Rahim R, Niggemeyer LE, Kossmann T. Management of blunt bowel and mesenteric injuries: Experience at the alfred hospital. Eur J Trauma Emerg Surg. 2009;35(5):482. doi: 10.1007/s00068-0098078-4. [PubMed: 26815216].

24. Frick EJ, Pasquale MD, Cipolle MD. Small bowel and mesentery injuries in blunt trauma. I Trauma. 1999; 46(5):920-6. doi: 10.1097/00005373-199905000-00024. [PubMed: 10338413].

25. Govender M, Madiba TE. Current management of large bowel injuries and factors influencing outcome. Injury. 2010; 41(1):58-63. doi: 10.1016/j.injury.2009.01.128. [PubMed: 19535065].

26. Liao $\mathrm{CH}$, Hsieh FJ, Chen $\mathrm{CC}$, Cheng $\mathrm{CT}$, Ooyang $\mathrm{CH}$, Hsieh $\mathrm{CH}$, et al. The prognosis of blunt bowel and mesenteric injury-the pitfall in the contemporary image survey. J Clin Med. 2019;8(9):1300. doi: 10.3390/jcm8091300. [PubMed: 31450573].

27. Allen GS, Moore FA, Cox CS, Wilson JT, Cohn JM, Duke JH Hollow visceral injury and blunt trauma. J Trauma. 1998;45:(1):69-75. doi: 10.1097/00005373-19980700000014. [PubMed: 9680015].

28. Xeropotamos NS, Nousias VE, Ioannou HV, Kappas AM. Mesenteric injury after blunt abdominal trauma. Eur J Surg. 2001;167(2):106-9. doi: 10.1080/110241501750070547. [PubMed: 11266248].

29. Harmston C, Ward JB, Patel A. Clinical outcomes and effect of delayed intervention in patients with hollow viscus injury due to blunt abdominal trauma: a systematic review. Eur J Trauma Emerg Surg. 2018;44(3):369-76. doi: 10.1007/s00068-018-0902-2. [PubMed: 29302699].

30. Fang JF, Chen RJ, Lin BC, Hsu YB, Kao JL, Kao YC, et al. Small bowel perforation: is urgent surgery necessary? J Trauma. 1999;47(3):515-20. doi: 10.1097/00005373-19990900000014. [PubMed: 10498306].

31. Bensard DD, Beaver BL, Besner GE, Cooney DR. Small bowel injury in children after blunt abdominal trauma: is diagnostic delay important? I Trauma. 1996;41(3):476-83. doi: 10.1097/00005373-199609000-00015. [PubMed: 8810966].

32. Hughes TM, Elton C, Hitos K, Perez JV, McDougall PA. Intraabdominal gastrointestinal tract injuries following blunt trauma: The experience of an Australian trauma centre. Injury. 2002;33(7):617-26. doi: 10.1016/s0020-1383(02) 00068-2. [PubMed: 12208066].

33. Bège $T$, Brunet $C$, Berdah SV. Hollow viscus injury due to blunt trauma: A review. J Visc Surg. 2016;153(4Suppl):61-8. doi: 10.1016/j.jviscsurg.2016.04.007. [PubMed: 27209078].

34. Schnüriger B, Lam L, Inaba K, Kobayashi L, Barbarino R, Demetriades D. Negative laparotomy in trauma: are we getting better? Am Surg. 2012;78(11):1219-23. [PubMed: 23089438]. 